\title{
14
}

\section{Synthesising models, theories and frameworks for public policy: Implications for the future}

\author{
Allan McConnell
}

\section{Introduction}

The worlds of academic theory and policy practice are often portrayed as two remote endeavours, each barely acknowledging the other and more comfortable with scepticism than mutual respect. In this volume's first chapter, the editors identify the key goal of the book: to shed light on this 'two worlds' relationship and examine actual and potential opportunities that would help policy theory speak to practitioners and vice versa. It is clear from all the contributions in this volume that, while stereotypes do indeed have some basis in reality, there is also goodwill on both sides and, indeed, there are not inconsiderable elements of enthusiasm. The present chapter is a step along the road towards the goals of the book. It reflects on the chapters in aggregate, drawing out five general themes and examines reasons to be cautious and realistic, but also reasons to be pragmatically optimistic. 


\section{Theories and practitioners have their limits: We need realistic expectations}

Much of public life and public policy is full of promises-occasionally 'cast iron' ones, such as UK Prime Minister Boris Johnson's guarantee that Brexit would be delivered by 31 October 2019. Politicians and policymakers can produce, and get caught up in, the heady rhetoric of partisanship and cultures of 'we can deliver'. Academia also talks of 'ground breaking' and 'truly innovative' research. Yet, despite many undoubted achievements on all sides, it is worth making a key but often-ignored point. No one has perfect solutions for all scenarios and, therefore, it is important to have realistic expectations of what is possible. One might call this a pragmatic optimism, rather than a blinded optimism that can never be fulfilled. The issues are huge, but let us consider a few brief points that typify.

Our first port of call is to consider the limits of academic theories of public policy and policy processes. In policy studies, there is no 'theory of everything' that would be able to capture the circumstances and variables of every scenario, accompanied by a definitive statement on causal factors and a prediction of what might happen in any particular situation. As Cairney and Geyer (2015) argue, policy systems and their environments are characterised by multiple, complex interdependencies and individual behaviours that can-even with small variations-lead to innumerable outcomes. For example, I cannot think of any academic theory that could be used to say if we do X it can be guaranteed that a new road tunnel will be built in exactly three years time' or 'we can set welfare benefits levels at $\mathrm{Y}$ and it can be guaranteed that $\mathrm{Z}$ number of children will no longer live in poverty'. Implementation is a relatively neglected aspect of policy processes, yet huge vulnerabilities can incubate because there are a multitude of small issues with potentially large and damaging consequences (such as ambiguous wording in policy goals or training shortfalls around issues of service delivery). Successful implementation of any program cannot be guaranteed (Hill \& Hupe 2009). Indeed, one of the lessons of Wildavsky (1984), in recognising the 'muddiness' of competing evidence bases, issue complexity and differences in underlying assumptions and values, is the absence of a 'secret' to policy analysis that will apply at all times in all contexts. Understanding policy involves craft and informed judgement. 
In a similar vein, many of the chapters in this book point to academia being limited in its relevance to the world of practitioners. In research undertaken for Chapter 9, Mackie (this volume) conducted interviews with policymakers in a study of environmental policies over the period 1993-2013. She found that they rarely drew on policy frameworks or concepts to help inform their work. A survey of policy practitioners in New Zealand, conducted by Löfgren and Bickerton (this volume, Chapter 5) found that the biggest barrier to using academic outputs was being unable to convert academic frameworks into policy outputs. They also found that some of the main constraints faced by practitioners in using academic theories included academic work being too technical, abstract, difficult to apply and difficult to interpret.

Despite such misgivings, we should not 'throw the baby out with the bathwater'. Although some academics may be very protective of their theoretical models and assumptions, it is better, I would argue, if we think of these theories as suggesting tendencies rather than iron laws. For example, in a recent book on policy success, Luetjens, Mintrom and 't Hart (2019) argue that there are six emerging patterns in successful projects (including problems being well-defined and allowing issues to 'ripen' before acting), but they acknowledge that the presence of such characteristics increases the likelihood of success rather than guaranteeing it. This example typifies the contribution that public policy scholars and theories can make. Overall, therefore, we should have realistic expectations about what academic theory can bring rather than thinking it has a ready-made solution for every policy problem or every scenario that a decision-maker faces.

A parallel line of reasoning can also be applied to policy practitioners who do not have guaranteed interventions for every policy issue or decision-making predicament. In Chapter 1, Mercer, Ayres, Head and Wanna (this volume) note a broader dissatisfaction among politicians and commentators in relation to lack of policy capacity on the part of public servants. There is undoubtedly some validity in this view, and it makes sense to have a public service that is fit for the purpose of addressing the trials and tribulations of modern policymaking, which often encompass high complexity and political uncertainty in a world in which many policy challenges are multi-jurisdictional and global. But it also brings an undercurrent of unfortunate personalisation, as though 'weak' policy capacity can be attributed to the inherently weak attributes or the behavioural inclinations of public servants. As cited in Chapter 7 by Edwards (this volume), the head of the Department of Prime Minister 
and Cabinet asked public servants to: 'Think big. Aim high. Experiment. Be Ruthless'. Yet, as Halligan (2019) argues, the reality is that the public service is typically risk-averse because it operates in highly politicised environments with major consequences for failure.

To take this point further, rhetoric with inferences that public servants are part of the problem because they do not fully grasp complex situations and cannot navigate them with relative ease, belies the reality that carving out policy 'solutions' and finding a way through a maze of ambiguous and contested issues can be tough-even for the most experienced public servants. One reason is that many policy problems, such as Indigenous disadvantage, drug abuse and gender inequality, are 'wicked', because there are high levels of contestation on the root causes of the problem, the interventions needed to address them, as well as high levels of uncertainty about whether any 'solution' will actually work (Head 2008; Head \& Alford 2015; McConnell 2018). Practitioners may also have 'boundedly rational' limits (such as lack of time and resources) in being able to comprehensively examine every issue from every angle and work out the most appropriate means of intervention. Indeed, as Edwards (this volume) argues in Chapter 7: 'too often policy development stalls because policy advisers put policy options to ministers without taking account of the values that will govern their decisions'. Politics is part of the landscape of policy processes, and it seeps by a process of osmosis into every area of the public sector. Politics is not just 'party politics' or 'what the minister wants'. Politics is also the business of governing, in which governments and public authorities need to manage crowded policy agendas and issues that exceed their capacity to prioritise and deal forcefully with each one. Hence, much of the business of governing is about redefining issues, making them manageable and even pushing them to the margins (or beyond) of policy agendas in the hope that they will stay there-at least for a while (McConnell \&'t Hart 2019; Stringer \& Richardson 1979).

Importantly, we should not dismiss the value of practitioner insights just because they do not have guaranteed solutions for every situation. Many have years of experience across multiple portfolios and epitomise what Rhodes (2016, p. 638) describes as the craft skills of 'counseling, stewardship, prudence, probity, judgement, diplomacy, and political nous'. Further examination of such issues is provided below, but-mirroring the academic experience-the point is that practitioners are well placed to exercise good judgement on what will tend to work and what will not. We should not expect them to have 'all the answers', in the same 
way that we should not expect academic theories to conceptualise and provide guaranteed practical advice for every scenario. In some instances, the combined value can be greater than their individual contributions, but the best way of gaining insights and advancing the relationship is through realistic and achievable (rather than utopian) assumptions about what is possible.

\section{The two worlds are not completely separate: Beware of stereotypes}

As Mercer, Ayres, Head and Wanna indicate in Chapter 1, there is a widely held belief in the contrast between the 'ivory tower world' of academia and the 'real world' of policy practitioners. The former is often considered to be focused on explaining broader trends and patterns, too frequently in abstract and difficult-to-understand terms that are divorced from the realities of policy practice. Meanwhile, practitioners are focused on 'doing' and addressing day-to-day challenges (from the strategic to the operational), with little time to read and interpret theoretical frameworks that have potentially limited value. Indeed, such a distinction can be inferred from work on why practitioners do not use academic research (albeit not the only reason). As Löfgren and Bickerton outline in Chapter 5 , based on their empirical studies in New Zealand on the extent to which policy practitioners draw on academic research, some of the constraints include academic work being too technical, too abstract, difficult to apply and difficult to interpret.

There is undoubtedly some distance between these two worlds, cultivated not least by the respective roles and jobs performed by academics and policy practitioners. As Threlfall and Althaus suggest in Chapter 2, the disconnect is fuelled by institutional factors such as (some) academics not valuing practical effects, and practitioners being unable to access articles that are hidden behind paywalls. Nevertheless, a persistent theme throughout this volume is the existence of spaces of intersection, akin to overlapping circles in a Venn diagram. As indicated in Chapter 1 by Mercer, Ayres, Head and Wanna, and Chapter 4 by Wanna, there is a rich seam of policy programs across many Australian universities with a particularly important one being the Australia and New Zealand School of Government (ANZSOG) - a leader in providing boutique training and study for senior public servants. In Chapter 2, Threlfall 
and Althaus point to the artificiality of a theory-practice divide because the two realms are part of a shared enterprise with each involved in critical thinking and reflection to build understanding and seek policy improvement. Newman, Cherney and Head (2015), in a major survey of over 2,000 public officials (supported by 16 in-depth interviews), found considerable overlap and diversity. Dissemination practices varied within academia, and uptake of academic research varied within the practitioner world.

An important point, but one which is barely mentioned in this volume, is that 'on-the-job' learning comes with the inference that public servants are 'blank slates' when they arrive in the public sector. Clearly this is not the case and, indeed, apart from their lived experiences and reflections, almost two-thirds of the Australian Public Service have an undergraduate degree or higher, and many of these will be in the social sciences broadly defined (Australian Public Service Commission 2016). ${ }^{1}$ A key value of such degrees is being able to navigate uncertainty, ambiguity, competing evidence bases, opposing arguments and accept that there are typically no magical understandings. Such issues of complexity and differences of opinion are at the very heart of public policy. Therefore, even without exposure to policy theories per se, many public servants already have-via their prior education - some of the transferable skills needed to navigate complex and fast-moving public sector issues.

Overall, therefore, while there are credible reasons to distinguish between the world of academic theory development and the world of policy practitioners, we should beware of over-amplifying the differences and stereotyping the separation.

\section{High-profile theories are the tip, not the iceberg: Opportunities are greater than we think}

One of the clear signals throughout this volume is the existence of a handful of theories that are pervasive in many public sectors (see particularly Chapter 3 by Mercer). Arguably, at the top of the list is the policy cycle

1 This figure is calculated from the data in Table 21 and excluded public servants for which no educational background was available. 
or stages approach, which has its origins in Lasswell $(1956,1971)$ and the development of policy sciences in the decades after World War II in which breaking down the policy decision process into a sequence of quasi-rational tasks (such as intelligence, promotion and prescription) was a means of harnessing policy expertise for societal betterment. Chapter 12 by Maurer provides a clear example of the value of the policy cycle as the starting point for the development of a policy handbook for the Department of Communications.

High on the radar of policy practitioners also is Mark Moore (1995, 2013) and his public value framework. Moore provides a guide to public sector strategy, based on managers aligning the goals of delivering substantive public value, enabling legitimacy/political sustainability, and ensuring operational/administrative feasibility. At the heart of the public value framework is the vision of a positive role for the public sector, as an antidote to the burgeoning rejection of 'big government' that had begun under the Reagan presidency in the US (as exemplified in Osborne \& Gaebler [1992]). As indicated by Mercer, Ayres, Head and Wanna in Chapter 1, the public value framework has, despite some criticism and ambiguities, resonated for many public servants by helping legitimate, guide and enable policy development. Indeed, the very ambiguity of the term 'public value' may be, drawing on Stone (2012) from her work on policy symbols and meaning, the 'glue' that allows different views and interpretations to cohere.

Incrementalism, a concept originating with Lindblom $(1959,1965)$ and taken further by Braybrooke and Lindblom (1970), is another pervasive theory, with its emphasis on the value of incremental change driven by the administrative practicalities and democratic principles of bargaining, negotiation and trade-offs. As argued by Mercer in Chapter 3, it probably remains one of the best descriptors of how policy is made, despite being challenged by the new public management model, with its emphasis on competition, efficiency and cost-containment.

The multiple streams framework originating with John Kingdon (1984, 2011) is perhaps not so prevalent, but it certainly resonates with many. Kingdon shows how timing is crucial. On occasions such as new public moods, changes of government or crises, problems, potential solutions and politics can coalesce to produce 'windows of opportunity' that can act as vehicles for change or, equally, can be closed when the circumstances are not aligned. In Chapter 9, Mackie indicates how 
the framework was highly useful in helping uncover the intent and motivations of public officials. Kingdon's multiple streams framework is simple and accessible in making us think about an idea whose time has come' (Kingdon 2011, p. 1).

There are certainly other theories and concepts to be found in the public sector. Some are scattered throughout this book, including wicked problems (Ritchie this volume, Chapter 10), evidence-based policymaking (Threlfall \& Althaus this volume, Chapter 2), policy success and failure (Mackie this volume, Chapter 9) and the eight-fold path of policy analysis (Gilding this volume, Chapter 11) Yet, there are others not mentioned (such as nudge theory and risk management) as well as numerous theoretical frameworks with insights around issues such as accountability, transparency, resolving intractable controversies, policy design, policy inaction and learning, as well as frameworks addressing sectoral specific issues, such as disability, farming, security, transport and housing.

There is no suggestion here that practitioners should draw on insights from such theoretical frameworks. As we know, public servants have difficulty in accessing them or considering them, for whatever reason, to be of practical value. Rather, the point to be made is that academic insights are more than just a handful of well-travelled concepts that circulate routinely within the public sector and appear regularly in workshops. They do not equate with academia, in the same way that a few top Hollywood actors do not equate with the acting profession as a whole. Hence, the potential for academic theories to add value to the work of the public sector is much greater than we might think.

\section{Using theory is not all or nothing: Minimalism and flexibility can be of high value}

Academic theories may be seen by some as grand, rigid and written for academic purposes rather than practitioner relevance. Notwithstanding the veracity of this point for many academic works, some can offer insights that help inform others who may use these in deep or light ways, as they see fit. Therefore, academic theories do not need to be implanted in the public sector as though they are intellectual experiments. Many chapters in this book reveal theories and concepts that are used in partial, 
minimalist ways, while adapting to the particular context in which they are considered to be of value. Chapter 3 by Mercer points to the value of 'rules of thumb'. Chapter 8 by Ayres, a senior public servant with well over a decade of experience, sets out in detail how his work and leadership across various social policy departments, was shaped by modifying the core elements and principles of the policy cycle. Gilding, a policy practitioner with over 20 years experience across a range of portfolios, outlines in Chapter 11 how she was able to adapt an array of policy models into a 'blended' approach, including the policy cycle and Moore's public value approach.

One of the lessons of the current volume, therefore, is that academic theories and concepts can be useful and flexible simply by helping to provide insights into the opportunities/risks of different approaches to tackling policy challenges. Cairney (2013) addresses this issue in a major work on what we should do with multiple policy theories, each tackling issues from different directions and underpinned by different assumptions about how we understand the world. Hence, rather than searching for a grand unifying 'theory of everything', or engaging in endless comparisons between 'apples and oranges', we should be comfortable with theory offering 'insights'. Indeed, using 'just enough' theory, and being flexible in doing so to fit practitioner purposes, can be worth the investment. In fact, Cairney's chapter in this volume (Chapter 13) points to the value of theory as a novel lens to help think about practical problems, rather than being a blueprint for action. It is clear that academic analyses can help inform the 'real world' of thinking about, and addressing, complex social challenges. In Chapter 7, Edwards recounts her time as a policy adviser in the Hawke-Keating years and suggests that many major social policy initiatives may not have seen the light of day if not for the involvement of academic researchers at multiple stages of the policy process.

\section{The two worlds do not collide as much as we think: Sharing the same space can often be successful}

Following on from the above, it is clear that there are useful synergies between the two worlds and that the outcomes can be successful. For example, the policy cycle remains the most pervasive and useful concept in the Australian public sector, exemplified in the success of the Australian 
policy handbook by Althaus, Bridgman and Davis (2018), which is now in its sixth edition with sales in excess of 30,000 (see particularly Mercer, Ayres, Head \& Wanna this volume, Chapter 1). Its strength, despite much critique, is that it is a starting point for grasping some of the core ingredients of the policy processes (from initial problem definition through to implementation and evaluation). It also provides a normative starting point in seeking to recommend a sense of order to how policymakers can address undesirable social conditions/policy problems.

The concept of public value has become a mainstay in ANZSOG's Executive Master of Public Administration and Executive Fellows Program. As Barrett indicates in Chapter 6, the public value approach has been a useful means of enabling parliamentary actors to think of themselves as public managers, rather than simply as custodians of parliament. In Chapter 12, Maurer outlines how he was tasked with producing a handbook for the Department of Communications that could be used for policy development. In doing so, he relied heavily on the policy cycle, with much success to the point that it became incorporated into everyday practice. Incrementalism has also been a useful tool in avoiding policy paralysis and proceeding pragmatically in policy development (Mercer this volume, Chapter 3). Certainly, there have been instances when the relationship did not work out, but shared spaces can bring about mutual benefit.

\section{Conclusion}

This volume has been exceptionally useful in airing and examining issues around the interface between academic theory and practitioners, as well as the capacity for, and constraints on, further synergies. It is clear to me that, while there is some understandable and legitimate truth in the distinction between the worlds of academic theory and policy practice, there is a danger in exaggerating the separation and diminishing areas of commonality. Both have an interest in trying to figure out what government does (and does not do) and both would like to see policy outcomes that are beneficial to society as a whole, regardless of whether they may disagree on the best means of doing so. Academics do not need to be practitioners and practitioners do not need to be academics. We should be realistic rather than utopian in our expectations. There is value in their differences, but there is also value and mutual benefit in exploring further opportunities for interaction and shared spaces. 


\section{References}

Althaus, C, Bridgman, P \& Davis, G 2018, The Australian policy handbook: A practical guide to the policy-making process, 6th edn, Allen \& Unwin, Crows Nest, NSW.

Australian Public Service Commission 2016, Shape of the APS, viewed 2 February 2020, www.apsc.gov.au/shape-aps.

Braybrooke, D \& Lindblom, CE 1970, A strategy of decision: Policy evaluation as social process, The Free Press, New York, NY.

Cairney, P 2013, 'Standing on the shoulders of giants: How do we combine the insights of multiple theories in public policy studies', Policy Studies Journal, vol. 41, no. 1, pp. 1-21, doi.org/10.1111/psj.12000.

Cairney, P \& Geyer, R 2015, 'Introduction', in P Cairney \& R Geyer (eds), Handbook on policy complexity, Edward Elgar, London, UK.

Halligan, J 2019, 'Nadir or renaissance for the Australian Public Service?', in M Evans, M Grattan \& B McCaffrie (eds), From Turnbull to Morrison: The trust divide, Melbourne University Press, Melbourne, Vic.

Head, BW 2008, 'Wicked problems in public policy', Public Policy, vol. 3, no. 2, pp. 101-18.

Head, BW \& Alford J 2015, 'Wicked problems: Implications for public policy and management', Administration \& Society, vol. 47, no. 6, pp. 711-39, doi.org/ 10.1177/0095399713481601.

Hill, M \& Hupe, P 2009, Implementing public policy: An introduction to the study of operational governance, 2nd edn, SAGE, London, UK.

Kingdon, JW 1984, Agendas, alternatives and public policies, Little, Brown and Company, Boston, MA.

Kingdon, JW 2011, Agendas, alternatives and public policies, 2nd edn, Longman, Boston, MA.

Lasswell, HD 1956, The decision process: Seven categories of functional analysis, University of Maryland, College Park, MA.

Lasswell, HD 1971, A pre-view of policy sciences, Elsevier, New York, NY.

Lindblom, CE 1959, 'The science of "muddling through", Public Administration Review, vol. 19, no. 2, pp. 79-88, doi.org/10.2307/973677. 
Lindblom, CE 1965, The intelligence of democracy, The Free Press, New York, NY.

Luetjens, J, Mintrom, M \& 't Hart, P (eds) 2019, Successful public policy: Lessons from Australia and New Zealand, ANU Press, Canberra, ACT, doi.org/ 10.22459/SPP.2019.

Moore, MH 1995, Creating public value: Strategic management in government, Harvard University Press, Cambridge, MA.

Moore, M 2013, Recognizing public value, Harvard University Press, Cambridge, MA, doi.org/10.4159/harvard.9780674067820.

McConnell, A 2018, 'Rethinking wicked problems as political problems and policy problems', Policy \& Politics, vol. 46, no. 1, pp. 165-80, doi.org/10.1332/ $030557317 X 15072085902640$.

McConnell, A \& 't Hart, P 2019, 'Inaction and public policy: Understanding why policymakers "do nothing"', Policy Sciences, vol. 52, no. 4, pp. 645-61, doi.org/10.1007/s11077-019-09362-2.

Newman, J, Cherney, A \& Head, B 2015, 'Do policy makers use academic research? Reexamining the "two communities" theory of research utilization', Public Administration Review, vol. 76, no. 1, pp. 24-32, doi.org/10.1111/ puar. 12464 .

Osborne, D \& Gaebler, T 1992, Reinventing government: How the entrepreneurial spirit is transforming the public sector, Addison-Wesley, Reading, MA.

Rhodes, RAW 2016, 'Recovering the craft of public administration', Public Administration Review, vol. 76, no. 4, pp. 638-47, doi.org/10.1111/puar.12504.

Stone, D 2012, Policy Paradox, 3rd edn, WW Norton, New York, NY.

Stringer, JK \& Richardson, JJ 1979, 'Managing the political agenda: Problem definition and policy making in Britain', Parliamentary Affairs, vol. 33, no. 2, pp. 23-39, doi.org/10.1093/oxfordjournals.pa.a051831.

Wildavsky, A 1984, Speaking truth to power: The art and craft of policy analysis, Transaction, New Brunswick, NJ. 
This text is taken from Learning Policy, Doing Policy: Interactions Between Public Policy Theory, Practice and Teaching, edited by Trish Mercer, Russell Ayres, Brian Head and John Wanna, published 2021 by ANU Press, The Australian National University, Canberra, Australia.

doi.org/10.22459/LPDP.2021.14 